\title{
Electrophysiological evaluation of oropharyngeal swallowing in myotonic dystrophy
}

\author{
C Ertekin, N Yüceyar, İ Aydoğdu, H Karasoy
}

\begin{abstract}
Objective-Oropharyngeal dysphagia is a common feature of patients with myotonic dystrophy and is not usually perceived due to their emotional deficits and lack of interest. The aim was to show the existence and frequency of subclinical electrophysiological abnormalities in oropharyngeal swallowing and to clarify the mechanisms of dysphagia in myotonic dystrophy.

Methods-Eighteen patients with myotonic dystrophy were examined for oropharyngeal phase of swallowing by clinical and electrophysiological methods. Ten patients had dysphagia whereas 11 patients had signs and symptoms reflecting CNS involvement. Four patients with myotonia congenita and 30 healthy volunteers served as controls. Laryngeal movements were detected by means of a piezoelectric sensor. EMG activities of the submental muscle (SM-EMG) and needle EMG of the cricopharyngeal muscle of the upper eosophageal sphincter (CP-EMG) were also recorded during swallowing. Results-In about $70 \%$ of the patients with myotonic dystrophy, the existence of oropharyngeal dysphagia was indicated objectively by means of the technique of "dysphagia limit" and by clinical evaluation. Duration of the swallowing reflex as defined by the laryngeal relocation time (0-2 time interval) and submental muscle excitation as a part of the swallowing reflex (A-C interval) were significantly prolonged in patients with myotonic dystrophy, especially in dysphagic patients. Triggering time of the swallowing reflex (A-0 interval) also showed significant prolongation, especially in the patients having both dysphagia and CNS involvement. During swallowing, CP muscle activity was abnormal in $40 \%$ of the patients with myotonic dystrophy.

Conclusion-Both myopathic weakness and myotonia encountered in oropharyngeal muscles play an important part in the oral and the pharyngeal phases of swallowing dysfunction in myotonic dystrophy. It was also suggested that CNS involvement might contribute to the delay of the triggering of the swallowing reflex and some abnormal EMG findings in the CP sphincter, resulting in oropharyngeal dysphagia in myotonic dystrophy. (F Neurol Neurosurg Psychiatry 2001;70:363-371)
\end{abstract}

Keywords: myotonic dystrophy; oropharyngeal dysphagia; central nervous system; electrophysiological evaluation
Myotonic dystrophy (MyD) is the most common adult form of muscular dystrophy and pneumonia was reported to be the most common cause of death in these patients. ${ }^{1}$ Pneumonia in MyD results from a multiplicity of problems. Oropharyngeal dysphagia and oesophageal motility disorders were found to be the most important reasons causing aspiration pneumonia. ${ }^{2-6}$ Dysphagia may be even a more prominent problem when the swallowing disorder seems to be present early in the course of disease but is not usually subjectively perceived until the advanced stages of disease are reached. ${ }^{6}$

Patients with MyD often exhibit disorders of personality and impairment of intellectual and cognitive functions, especially lack of interest in their disease. ${ }^{7}$ This might play a part in the unawareness of the swallowing dysfunction in these patients. Therefore, it is necessary to evaluate the oropharyngeal deglutition and oesophageal motility in every patient with MyD.

Alterations in pharyngeal and oesophageal functions have been reported in $\mathrm{MyD}$ on the basis of both manometric and radiographic studies. ${ }^{2}{ }^{68-11}$ These methods are important; however they are time consuming, expensive, and sometimes difficult to apply, especially when patients will not cooperate. Furthermore, the physiological basis of swallowing dysfunction is not clearly understood, as some conflicting results exist. ${ }^{9-11}$ The oropharyngeal swallowing function in $\mathrm{MyD}$ has not been studied by electrophysiological techniques. Therefore we had two aims in this study; the first was to show the existence and frequency of subclinical physiological abnormalities in oropharyngeal swallowing, the second was to consider the mechanisms leading to oropharyngeal dysphagia in MyD.

\section{Patients and methods}

Eighteen patients with myotonic muscular dystrophy were studied. Diagnosis of MyD was based on clinical and electrophysiological findings and the history of the patients' pedigrees. The severity of disease was classified from 1 to 5 using the muscular disability rating scale described by Mathieu et al. ${ }^{12}$ The mean age of the patients was 38.8 (range 19-66 years). Eight were women. The mean duration of the disease was 14.3 years (range 1-35 years). Clinical features of all patients are summarised in table 1. Clinical diagnosis of dysphagia was defined when there were persistent symptoms (nasal regurgitation, frequent necessity to clear the throat, feeling of food in the nasopharynx) obtained from their questionnaire and abnor- 
Table 1 Summary of the clinical features of patients with myotonic dystrophy

\begin{tabular}{|c|c|c|c|c|c|c|}
\hline Patient & Age/sex & $\begin{array}{l}\text { Duration of } \\
M y D(y)\end{array}$ & $\begin{array}{l}\text { MDR } \\
\text { scale }\end{array}$ & $\begin{array}{l}\text { Dysphagic } \\
\text { symptoms }\end{array}$ & $\begin{array}{l}\text { Other GI } \\
\text { symptoms }\end{array}$ & CNS Symptoms \\
\hline 1 & $23, \mathrm{~F}$ & 7 & 3 & + & + & AP, MRI \\
\hline 2 & $40, \mathrm{~F}$ & 3 & 3 & + & + & $\mathrm{AP}, \mathrm{EDS}, \mathrm{MRI}$ \\
\hline 3 & $23, \mathrm{M}$ & 16 & 2 & - & + & AP, BIQ, EDS \\
\hline 4 & $20, \mathrm{~F}$ & 5 & 2 & - & - & $\mathrm{AP}, \mathrm{BIQ}$ \\
\hline 5 & $42, \mathrm{M}$ & 27 & 3 & + & + & AP, EDS, MRI \\
\hline 6 & $33, \mathrm{M}$ & 23 & 4 & - & - & $\mathrm{AP}, \mathrm{BIQ}, \mathrm{EDS}$ \\
\hline 7 & $19, M$ & 12 & 2 & + & - & $\mathrm{AP}, \mathrm{BIQ}, \mathrm{EDS}$ \\
\hline 8 & $50, M$ & 35 & 4 & + & + & $\mathrm{AP}, \mathrm{BIQ}, \mathrm{EDS}, \mathrm{MRI}$ \\
\hline 9 & $54, \mathrm{~F}$ & 2 & 3 & - & - & $\mathrm{AP}, \mathrm{BIQ}, \mathrm{EDS}$ \\
\hline 10 & $46, \mathrm{M}$ & 26 & 3 & + & + & $\mathrm{AP}, \mathrm{BIQ}, \mathrm{EDS}, \mathrm{MRI}$ \\
\hline 11 & $39, M$ & 14 & 3 & + & - & $\mathrm{AP}, \mathrm{BIQ}, \mathrm{EDS}$ \\
\hline 12 & $49, \mathrm{M}$ & 5 & 3 & + & - & - \\
\hline 13 & $66, \mathrm{~F}$ & 23 & 4 & - & - & - \\
\hline 14 & $42, \mathrm{~F}$ & 1 & 1 & - & - & - \\
\hline 15 & $41, \mathrm{M}$ & 14 & 2 & - & - & - \\
\hline 16 & $31, \mathrm{~F}$ & 9 & 3 & + & + & - \\
\hline 17 & $45, \mathrm{M}$ & 30 & 3 & + & - & - \\
\hline 18 & $35, \mathrm{~F}$ & 5 & 4 & - & + & - \\
\hline
\end{tabular}
or mental retardation; $\mathrm{MRI}=$ abnormal findings by cranial $\mathrm{MRI}^{42-44}$; GI=gastrointestinal.

mal signs closely related to swallowing disorder (cough during swallowing, accumulation of saliva in the mouth, "wet" voice after swallowing water, nasal voice, palatal paresis, abnormal head posture during swallowing). The patients having uncertain symptoms but lacking any objective signs that could be related to swallowing were not considered to be dysphagic. Therefore 10 patients with dysphagia and eight patients without dysphagia were classified according to the clinical evaluation for dysphagia. Clinical and laboratory findings in patients were documented in detail in our neuromuscular unit and gastrointestinal symptoms and signs were especially evaluated by the clinic of gastroenterology.

Patients with MyD were also reclassified for their symptoms reflecting CNS involvement such as excessive daytime sleepiness, apathy, and mental retardation. ${ }^{13}{ }^{14}$ Their MRI findings are shown in table 1. Eleven patients had symptoms and signs suggesting CNS involvement (patient 1 to patient 11 in table 1 ).

Four patients with myotonia congenita were studied to clarify the pure effect of myotonia on the electrophysiological findings. Patients with congenital myotonia had generalised myotonia without any weakness determined by both clinical and EMG methods. They had clinically no dysphagia. Their mean age was 33 (range 17-40 years, all men).

The mean values and individual results of swallowing variables obtained from patients were compared with the mean values and ranges of 30 normal control subjects. (mean age 38.5; range 20-65 years, 15 women). The cricopharengeal (CP) muscle of the upper oesophageal sphincter was investigated in 13 patients with $\mathrm{MyD}$ and the results were compared with 20 normal control subjects with a mean age of 39.3 (range 22-61 years, 13 women). Informed consent was obtained from each patient. The investigation was approved by the ethics committee of our university hospital.

The methods used for the evaluation of dysphagia have been described previously. ${ }^{15}$ During the examination, the seated patient was instructed to hold his or her head in a neutral upright position. Swallows were initiated vol- untarily with the bolus (tap water) positioned on the tongue and the tip of the tongue touching the upper incisors. Swallow signals were recorded after the delivery of $3 \mathrm{ml}$ water through a graduated syringe. Mechanical upward and downward laryngeal movements during swallowing were detected by means of a piezoelectric sensor designed in our laboratory. This was a simple piezoelectric wafer with a $4 \times 2.5 \mathrm{~mm}$ rubber bulge fixed into its centre. The rubber bulge was placed on the coniotomy region between the cricoid and thyroid cartilages at midline. The sensor was taped onto the neck and its output signal was filtered (band pass $0.01-20 \mathrm{~Hz}$ ) and fed into one of the channels of the EMG apparatus (Medelec Mystro, MS-20, Surrey, UK). The submental muscle EMG (SM-EMG) was recorded by bipolar silver chloride EEG electrodes taped under the chin over the submental muscle complex (mylohyoid, geniohyoid, and anterior digastric muscles). Signals were filtered (band pass $100 \mathrm{~Hz}$ to $10 \mathrm{kHz}$ ), amplified, rectified, and integrated.

Cricopharyngeal muscle activity of the upper eosophageal sphincter was recorded with a sterile needle electrode (Medelec disposable needle electrode DMC-37) inserted through the skin at the level of the cricoid cartilage about $1.5 \mathrm{~cm}$ lateral to its palpable lateral border in the posterior median direction. The CP sphincter EMG (CP-EMG) was recorded together with the laryngeal movement signals under the same recording conditions as for the SM-EMG.

The laryngeal sensor gave two deflections with generally opposing polarity during each swallow. The first deflection of the laryngeal sensor represented the upward movement of the larynx and the second deflection its downward movement. The mid-region of the first deflection was stabilised on the oscilloscopic screen by using the delay line technique so that the deflections would appear at the same location of each sweep (about $800 \mathrm{~ms}$ after the onset of the sweep) throughout successive recordings. In this way, all electrophysiological events were displayed synchronously. The onsets of two deflections in the laryngeal sensor signal recordings were denoted as 0 and 2 . 
Table 2 Symptoms and signs of patients with myotonic dystrophy with regard to dysphagia

\begin{tabular}{lll}
\hline & With dysphagia & Without dysphagia $^{*}$ \\
\hline Difficulties in bolus formation and control & $8 / 10$ & $1 / 8$ \\
Feeling of food in the nasopharynx & $10 / 10$ & $0 / 8$ \\
Need to clear throat & $8 / 10$ & $0 / 8$ \\
Abnormal posture during swallowing & $8 / 10$ & $0 / 8$ \\
Nasal regurgitation & $6 / 10$ & $0 / 8$ \\
Cough during swallowing & $9 / 10$ & $0 / 8$ \\
Loss of weight & $3 / 10$ & $0 / 8$ \\
History of pneumonia & $2 / 10$ & $0 / 8$ \\
Slow laryngeal elevation & $6 / 10$ & $0 / 8$ \\
Weak involuntary cough & $8 / 10$ & $0 / 8$ \\
Dysphonia & $9 / 10$ & $2 / 8$ \\
Saliva accumulation in mouth & $5 / 10$ & $1 / 8$ \\
Palatal paresis & $6 / 10$ & $0 / 8$ \\
Facial weakness & $10 / 10$ & $8 / 8$ \\
Weakness in chewing muscles & $6 / 10$ & $0 / 8$ \\
Tongue weakness & $5 / 10$ & $3 / 8$ \\
Tongue myotonia & $7 / 10$ & $5 / 8$ \\
\hline
\end{tabular}

^ Number of patients having the sign or symptom/total number of dysphagic or non-dysphagic patients.

When the first deflection was stabilised on the EMG screen, the onset of the second deflection showed variability for the same subject during swallowing boluses of the same volume. This variability of the laryngeal downward movement was measured from the first peak of the superimposed traces of the second deflection to the last peak of them. This was called "swallowing jitter". ${ }^{16}$ As SM-EMG was activated by the laryngeal elevator muscles, their activity was considered to give information about the onset and duration of swallowing, ${ }^{17-19}$ and was denoted as the A-C interval. We also measured another important index called the A-O interval that was related to the triggering of the reflex swallow for the voluntarily initiated swallowing. This variable was the interval between the onset of the SM-EMG and the first deflection of the laryngeal sensor signal reflecting the upward movement of the larynx, which was one of the first events of the pharyngeal reflex swallowing. ${ }^{17}{ }^{20-24}$ The preanalysis time was set at $800 \mathrm{~ms}$ and the total sweep time was set at 2 or 5 seconds. At least five successive "swallowing signals" were recorded. The signals were examined either as a single trace or as the mean of several superimposed traces.

Piecemeal deglutition and dysphagia limit were also measured electrophysiologically. ${ }^{25}$ This test is based on determining piecemeal deglutition which is a physiological phenomenon that refers to the division of the bolus into two or three successive swallows. All patients were instructed to swallow doses of water gradually increasing in quantity from 1 to 20 $\mathrm{ml}$. The bolus volume causing the recurrence of the EMG and laryngeal sensor signals related to swallowing within 8 seconds was accepted as the sign of dysphagia limit.

Mean (SD) of all measured quantities were calculated. Student's $t$ test for independent samples was then applied for the comparison between patient groups and normal controls. Subgroups within the patient groups were compared both with normal controls and with each other by means of Duncan's multiple range variance analysis test. Spearman's correlation analysis test was performed for correlation studies. Significance was tested at the 5\% level.

\section{Results}

Ten patients with $\mathrm{MyD}$ had symptoms and signs closely related to dysphagia and pharyngolaryngeal muscle involvement (table 2). They all exhibited weakness and wasting in facial muscles. Weakness in jaw and tongue muscles was noted in six and five patients respectively and percussion myotonia in the tongue was elicited in seven out of 10 patients. All patients except one had a nasal voice and anteflexion posture was noticed during each swallow in eight patients. Their dysphagia was not severe enough to necessitate non-oral feeding despite their complaint of swallowing and the clinical signs of dysphagia such as cough during a swallow, wet voice after water drinking, and nasal regurgitation. The remaining eight patients with MyD had no complaint that could be attributed to dysphagia and the clinical examination of the swallowing function of these patients was almost always normal as shown in table 2 .

\section{DYSPHAGIA LIMIT}

Facial and tongue weakness and tonque myotonia occurred equally in both dysphagic and non-dysphagic patients with MyD (table 2 ). Therefore it is important to determine the oropharyngeal swallowing objectively in these patients. This was done by the technique of "dysphagia limit". The existence of dysphagia in MyD was indicated objectively by this electrophysiological evaluation. The normal control subjects could swallow up to $20 \mathrm{ml}$ of water without dividing the liquid material. Four patients with myotonia congenita without dysphagia also had normal limits of $20 \mathrm{ml}$ water. In nine dysphagic patients with $\mathrm{MyD}$, the bolus was divided into two or more alequots while swallowing the lesser volumes of water (fig 1).

In three of eight patients with $\mathrm{MyD}$ without clinical dysphagia, the dysphagia limit was lower than $20 \mathrm{ml}$ water. In one patient (patient 10) with clinical signs and symptoms suggesting dysphagia, the dysphagia limit was within normal limits. This patient had a clear anteflexion posture of his head for each volume of swallows. It was shown that the anteflexion posture or chin tuck posture of the head and neck facilitated or normalised swallowing. ${ }^{26-28}$ Consequently 12 out of 18 patients with MyD were accepted as having difficulty in their swallowing function from an electrophysiological point of view. Therefore about $70 \%$ of patients with MyD had problems during oropharyngeal swallowing determined both by clinical and electrophysiological evaluation.

LARYNGEAL MOVEMENTS AND SM-EMG DURING OROPHARYNGEAL SWALLOWING

The laryngeal elevation and relocation of the larynx (swallowing reflex) was significantly prolonged as shown by the $0-2$ time interval $(\mathrm{p}<0.05$, table 3 , fig 2$)$ and this variable was also individually prolonged in nine patients (seven dysphagic, two non-dysphagic) when compared with the age and sex matched normal subjects. Similarly the SM-EMG duration during swallowing (A-C interval) was significantly prolonged ( $p<0.001$, fig 2$)$. Although 


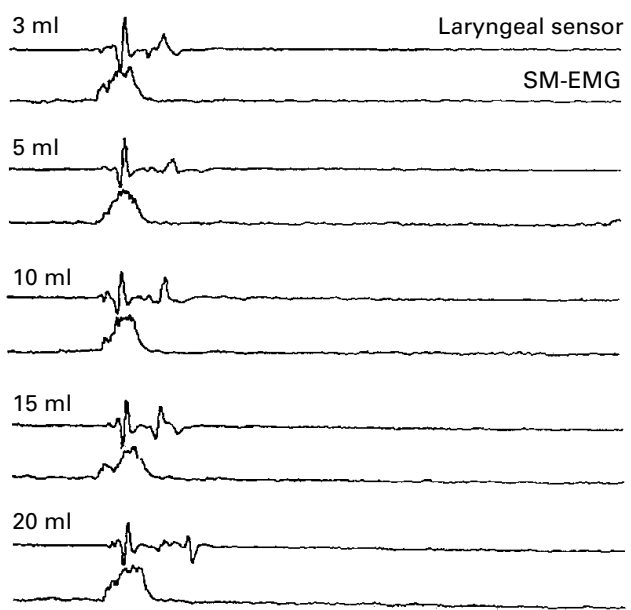

B Myotonic dystrophy with dysphagia

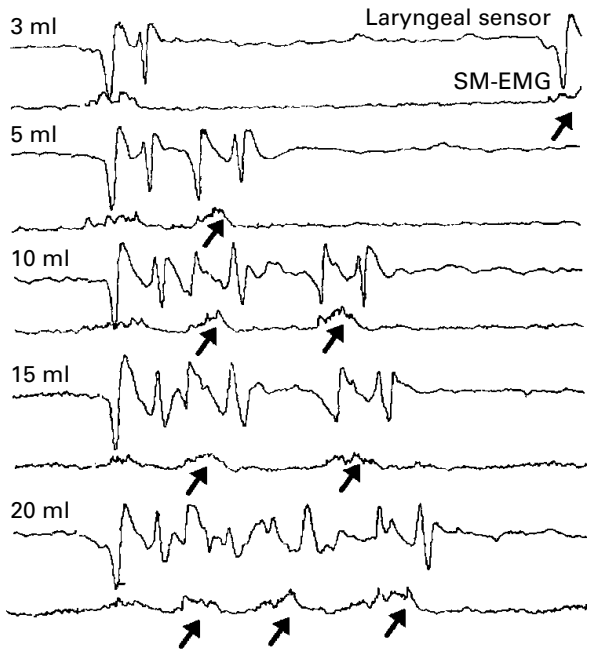

$50 \mu \mathrm{V}$

$1000 \mathrm{~ms}$

$100 \mu \mathrm{V}$

$1000 \mathrm{~ms}$

Figure 1 Laryngeal sensor signals (top traces in each pair) and integrated SM-EMG activities (lower traces in each pair) obtained from $(A)$ a normal subject and (B) a patient with MyD with dysphagia during swallowing of different amounts of water $(3-20 \mathrm{ml})$. The volume swallowed in a single attempt was up to $20 \mathrm{ml}$ in the normal subject whereas the patient began to divide the bolus even at $3 \mathrm{ml}$ water. The dysphagia limit was therefore $3 \mathrm{ml}$ for this patient. The bolus was divided more as the volume was increasing. Arrows indicate the second and subsequent swallows. Amplitude calibration 50 $\mu V$ for SM-EMG, time calibration $1000 \mathrm{~ms}$ in all traces. (The amplitude of the laryngeal sensor signal is irrevalent for this and subsequent figures.)

the longest duration of SM-EMG or 0-2 time interval was found in eight clinically dysphagic patients, similar and abnormal prolongation of these variables were also encountered in three patients without clinical dysphagia. When dysphagic and non-dysphagic patients were compared, the clinically dysphagic group had a significantly longer time interval only in A-C variables $(p<0,05)$. However, the $0-2$ time interval was significantly prolonged in dysphagic patients when compared with the normal control subjects $(\mathrm{p}<0.05)$ whereas no significance was found in non-dysphagic patients.

Three of the four patients with myotonia congenita did not differ from the normal subjects individually in $0-2$ and A-C variables. However, the A-C interval of the SM muscle excitation was found to be significantly prolonged in myotonia congenita when the results were compared statistically with the normal subjects $(\mathrm{p}<0.05)$.
The A-0 time interval indicating the triggering time of the pharyngeal reflex swallow ${ }^{24}$ was also statistically prolonged in patients with MyD ( $p<0.005)$ especially in clinically dysphagic patients $(p<0.05$, fig 2$)$. The nondysphagic patients with MyD did not differ from the normal control subjects. Interestingly, in patients with myotonia congenita, the A-0 interval was also significantly prolonged by comparison with normal subjects and in one patient with myotonia congenita the $\mathrm{A}-0$ interval was prolonged.

Swallowing jitter can be regarded as the variability in the swallowing apparatus and it can be an important measure of the safety of deglutition during swallowing boluses of the same volumes. ${ }^{15}{ }^{16}$ It was extremely high in five patients with $\mathrm{MyD}$, especially in dysphagic patients and the mean value of all patients was significantly prolonged $(\mathrm{p}<0.005)$ in comparison with normal control subjects (table 3, fig 2). Patients with myotonia congenita had

Table 3 Summary of the statistical results of patients with myotonic dystrophy and myotonia congenita compared with normal subjects

\begin{tabular}{|c|c|c|c|c|c|}
\hline & $\begin{array}{l}\text { Myotonic } \\
\text { dystrophy }(n=18)\end{array}$ & $\begin{array}{l}\text { Myotonic } \\
\text { dystrophy with } \\
\text { dysphagia }(n=10)\end{array}$ & $\begin{array}{l}\text { Myotonic } \\
\text { dystrophy without } \\
\text { dysphagia }(n=8)\end{array}$ & $\begin{array}{l}\text { Myotonia } \\
\text { congenita }(n=4)\end{array}$ & $\begin{array}{l}\text { Normal } \\
\text { subjects }(n=30)\end{array}$ \\
\hline \multirow[t]{2}{*}{$0-2$ Interval (laryngeal relocation time) } & $661(161)$ & $704(186)$ & $612(121)$ & $518(114)$ & $564(100)$ \\
\hline & $\mathrm{p}<0,05$ & $\mathrm{p}<0.05$ & NS & NS & \\
\hline \multirow[t]{2}{*}{ A-C Interval (SM-EMG duration) } & $1144(306)$ & $1250(285)$ & $1025(301)$ & $1124(618)$ & $850(123)$ \\
\hline & $\mathrm{p}<0.001$ & $\mathrm{p}<0.05$ & $\mathrm{p}<0.05$ & $\mathrm{p}<0.05$ & \\
\hline \multirow[t]{2}{*}{ A-0 Interval } & $400(185)$ & $437(164)$ & $359(208)$ & $454(236)$ & $263(119)$ \\
\hline & $\mathrm{p}<0.005$ & $\mathrm{p}<0,05$ & NS & $\mathrm{p}<0.05$ & \\
\hline \multirow[t]{2}{*}{ Swallowing variability (jitter) } & $133(74)$ & $150(79)$ & $114(68)$ & $57(30)$ & $71(40)$ \\
\hline & $\mathrm{p}<0.005$ & $\mathrm{p}<0.05$ & NS & NS & \\
\hline \multirow[t]{2}{*}{ SM-EMG amp } & $85(37)$ & $77(34)$ & $94(41)$ & $58(31)$ & $73(32)$ \\
\hline & NS & NS & NS & NS & \\
\hline
\end{tabular}

Statistical comparisons between the patients have not been included in the table (see text).

Statistical variables except SM-EMG amplitude $(\mu \mathrm{V})$ are in $\mathrm{ms}$ and the values are shown as mean (SD).

A- $0=$ the time interval at the onset of SM-EMG and the onset of laryngeal upward movements and reflects the time until triggering of the swallowing reflex. ${ }^{1522} 24$ 
Myotonic dystrophy without dysphagia

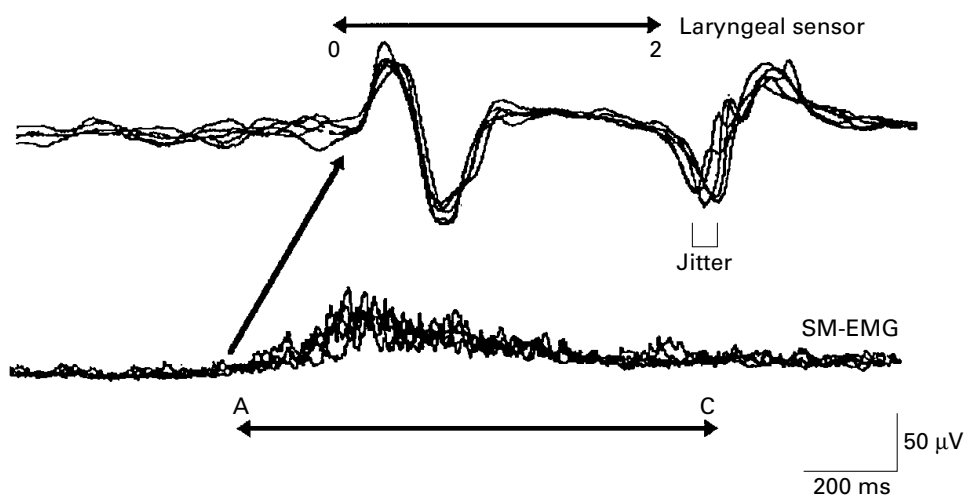

Myotonic dystrophy with dysphagia
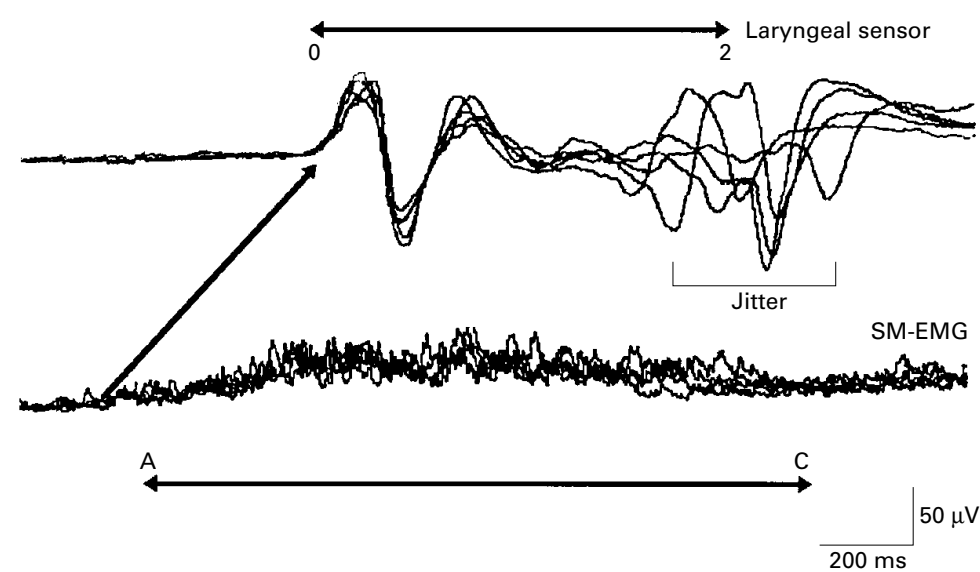

Figure 2 Laryngeal sensor signals (upper traces in each pair) and integrated SM-EMG (lower traces in each pair) in superimposed recordings obtained from a patient with MyD without dysphagia and a patient with dysphagia while swallowing $3 \mathrm{ml}$ water. The laryngeal relocation time ( $0-2$ time interval), duration of SM-EMG activity ( $A-C$ interval), swallowing jitter, and the triggering time interval of the swallowing reflex $(A-0$ interval) (oblique arrow) were obviously prolonged in the dysphagic patient. The points indicating the onset of the upward movement of the larynx (0) and downward movement (2) and the points indicating the onset and end of SM-EMG activity ( $A$ and $C$ respectively) are labelled according to the averaged recordings.

normal values of swallowing jitter varying between 20 and $90 \mathrm{~ms}$.

High variability of jitter and the increase in the A-0 interval were probably the results of the myotonic changes at the onset and end of contractions of the laryngeal elevation, especially in severely dysphagic patients. This was clear when the successive swallowing traces were examined one by one, as shown in fig 3 .

We could not find any correlation between dysphagia or electrophysiological variables and either the duration or the severity of the disease except for the significant correlation between the swallowing jitter and the duration of the disease $(r=0.60 ; \mathrm{p}<0.01)$. A significant correlation was also elicited between the presence of dysphagia and dysphagia limits, suggesting the high sensitivity of the test $(p<0.05)$. Eleven patients (table 1, patients 1-11) who had CNS symptoms and signs were compared with the remaining seven patients (table 1 , patients 11-17) who had no obvious symptoms and signs reflecting CNS involvement. The A-0 interval of the triggering of the swallowing reflex was prolonged both in patients with MyD with CNS signs and symptoms and in the patients without CNS involvement (449 (SD 66) $\mathrm{ms} ; 330$ (SD 45) ms, respectively). However this prolongation was significant only in patients with MyD with CNS involvement when compared with the normal subjects $(p<0.05)$. Other electrophysiological variables did not differ between the two groups with MyD.

CRICOPHARYNGEAL SPHINCTER EMG

The CP muscle of the upper oesophageal sphincter was investigated in 13 of the 18 patients with MyD. Behaviour of the CP-EMG was normal, as in normal control subjects both at rest and during swallowing in eight patients (two patients with and six patients without dysphagia). The resting tonic activity of CP muscle switched off for 400-500 ms (CPEMG pause) and during this time, the laryngeal upward and downward movements were coordinated. ${ }^{15}$ In the remaining five patients, the CP-EMG was pathological and all of the five patients had clinical dysphagia as well as clinical signs and symptoms reflecting CNS involvement. Figure 4 illustrates the CP-EMG recordings from two patients with MyD with dysphagia. The duration of the CP-EMG pause associated with the duration of the passage of the bolus into the oesophagus from the upper oesophageal sphincter tended to be shortened in three patients. The second abnormality of the CP sphincter was its premature closure. CP-EMG pause ended too early before the onset of the laryngeal downward movements in two patients. Figures 4 and 5 show the unexpected motor unit burst activity which appears within the CP-EMG pause and some remarkable variability of the tonic activity and foreburst just before the CP-EMG pause in a patient with MyD.

In summary, the CP sphincter muscle seemed to be intact in most patients with $\mathrm{MyD}$ with or without dysphagia. Although in the minority (about 40\%; all had dysphagia) the $\mathrm{CP}$ muscle of the upper oesophageal sphincter showed various abnormalities. During insertion of the needle electrode into the CP muscle, we rarely heard "dive bomber" in two patients, who also had other types of CP sphincter abnormalities as mentioned above. During swallowing, foreburst and rebound activities appearing around the CP-EMG pause sometimes tended to be of high amplitude and long duration without giving an impression of the dive bomber.

In the three patients with myotonia congenita evaluated, the CP-EMG activity was normal both in the resting condition and during swallowing.

\section{Discussion}

The swallowing impairment in myotonic dystrophy has been known since the disease was described by Steinert in $1909 .^{30}$ Dysphagia is an often encountered problem and has been reported with a prevelance between $25 \%$ and 
$80 \% .^{6}{ }^{31-34}$ We have found, using both clinical and electrophysiological criteria, that about $70 \%$ of patients with MyD have oropharyngeal swallowing problems.

The significant findings of the study can be gathered under five headings to clarify the mechanisms of oropharyngeal swallowing in myotonic dystrophy and these are discussed below.

(1) PIECEMEAL DEGLUTITION AND REDUCTION IN DYSPHAGIA LIMIT

We have found abnormal piecemeal deglutition and repetitive swallows in $67 \%$ of the patients (12 out of 18) investigated, as the first swallowing abnormality. This finding that can be considered as the oral phase of abnormality of dysphagia, ${ }^{2535}$ is not so surprising. Because the control of the bolus and its formation is mainly provided by the tongue, masticatory, buccal and submental muscles. If these muscles are weak, as in $\mathrm{MyD}$, the bolus will be divided into pieces and swallowed successively. ${ }^{23}{ }^{25}$ Despite this attempt, the residual bolus volume remaining in the space of the pharynx will escape either into the airway or down through the upper oesophageal sphincter, opened for a sec- ond time in a considerable time interval after the first swallow as we found in patients with MyD.

(2) DELAY IN THE TRIGGERING OF THE PHARYNGEAL SWALLOWING REFLEX

As a second swallowing abnormality, the interval between the onset of the SM-EMG (voluntarily onset) and the signal of first deflection of the laryngeal movement (reflex onset) - the A-0 interval-was prolonged during attempts to swallow in myotonic dystrophy in comparison with the normal subjects. This may reflect a delay in the triggering of the swallowing reflex. ${ }^{22}$ There might be several reasons for this delay in MyD as follows:

(a) It may be the result of poor tongue and submental muscle control due to the involvement of the striated muscles mentioned above. However we have previously shown in dysphagic patients with myasthenia gravis, ${ }^{35}$ and with polimyositis, ${ }^{23}$ that the triggering of reflex swallowing is not significantly disturbed or may even be normal as judged by the normality of the A-0 interval. Therefore a delay in triggering of the swallowing reflex is not restricted only to

Successive $3 \mathrm{ml}$ of water swallowing

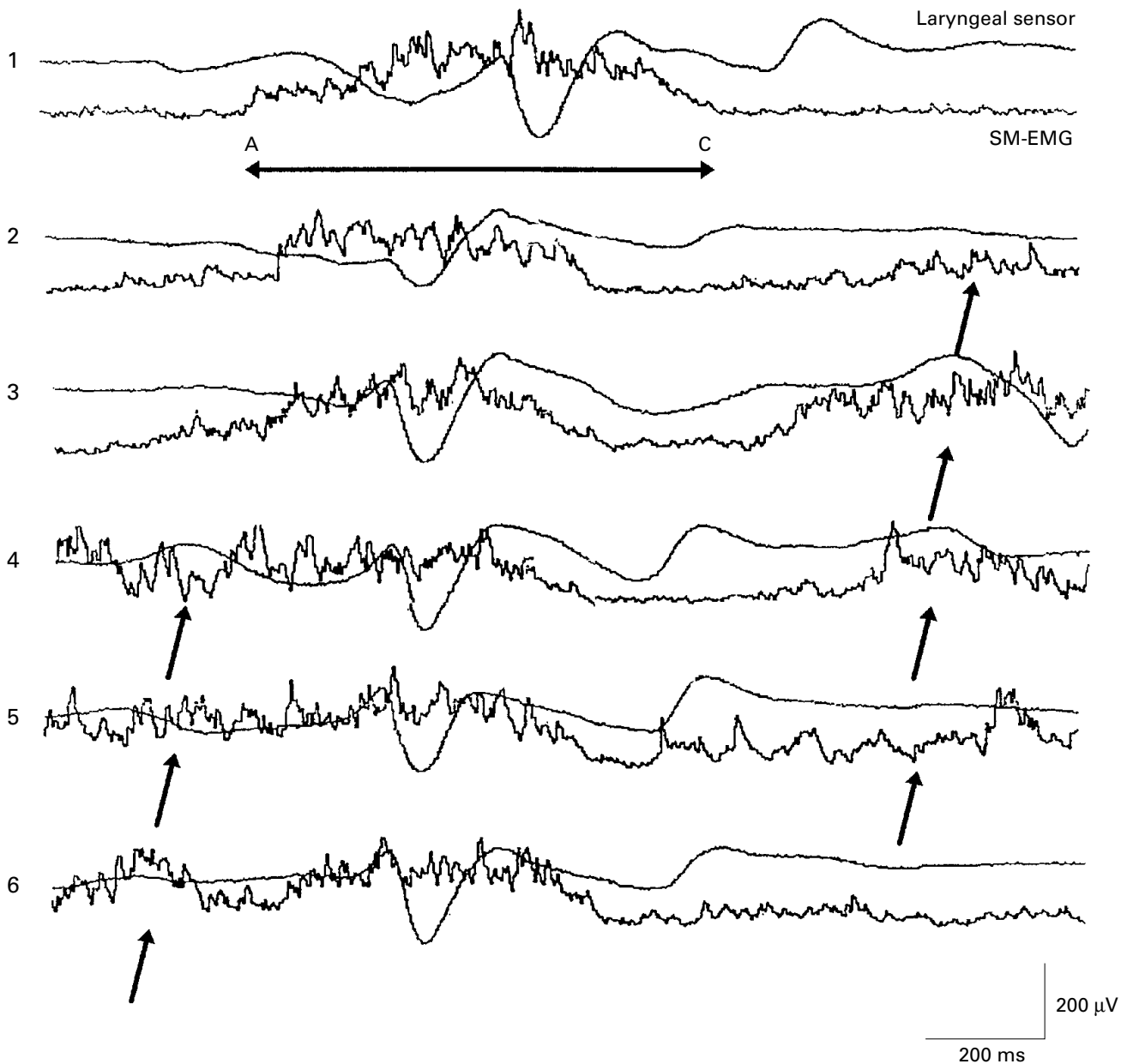

Figure 3 Six successive swallowing traces (laryngeal sensor signals in upper traces and SM-EMG activities in lower traces in each pair) while swallowing $3 \mathrm{ml}$ water in each time. Arrows indicate the myotonic changes in submental muscles either at the onset or at the end of SM-EMG activitiy ( $A$-C interval) during subsequent swallowing. 
the muscle weakness of the tongue and other muscles involved in $\mathrm{MyD}$.

(b) Mucosal and deeper mechanoreceptors in the oral-pharyngeal region and tongue and their sensory nerve fibres are obviously needed for the integrity of the triggering mechanism of swallowing. To our knowledge such an oral perception disorder has not been previously described in patients with MyD.

(c) Myotonia of the tongue and laryngeal elevator muscles such as SM muscles may have a role in delaying of the triggering mechanisms although a contrary view has also been proposed. ${ }^{9-11}$ In patients with $\mathrm{MyD}$ the irregularities of the SM-EMG traces were recorded more clearly if successive wet swallows were provided (fig 3 ). These patients had a significantly $(p<0.05)$ prolonged A-0 interval compared with the normal subjects. Therefore, a myotonic phenomenon might have some role in the delaying of the triggering and even in prolongation of the swallowing reflex. However, this does not mean that oropharyngeal muscle myotonia is the permanent cause of dysphagia because percussion myotonia of the tongue is not present in some patients with MyD with dysphagia (table 2). Furthermore, myotonia could not produce swallowing dysfunction in four patients with myotonia congenita.

(d) The corticobulbar pyramidal fibres seem to be responsible for initiating voluntarily induced swallows. Any type of involvement of corticobulbar fibres seen in suprabulbar palsies as in amyotrophic lateral sclerosis ${ }^{24}$ or lacunar states $^{36}$ produced delay in triggering of the swallowing reflex. Once the reflex is triggered
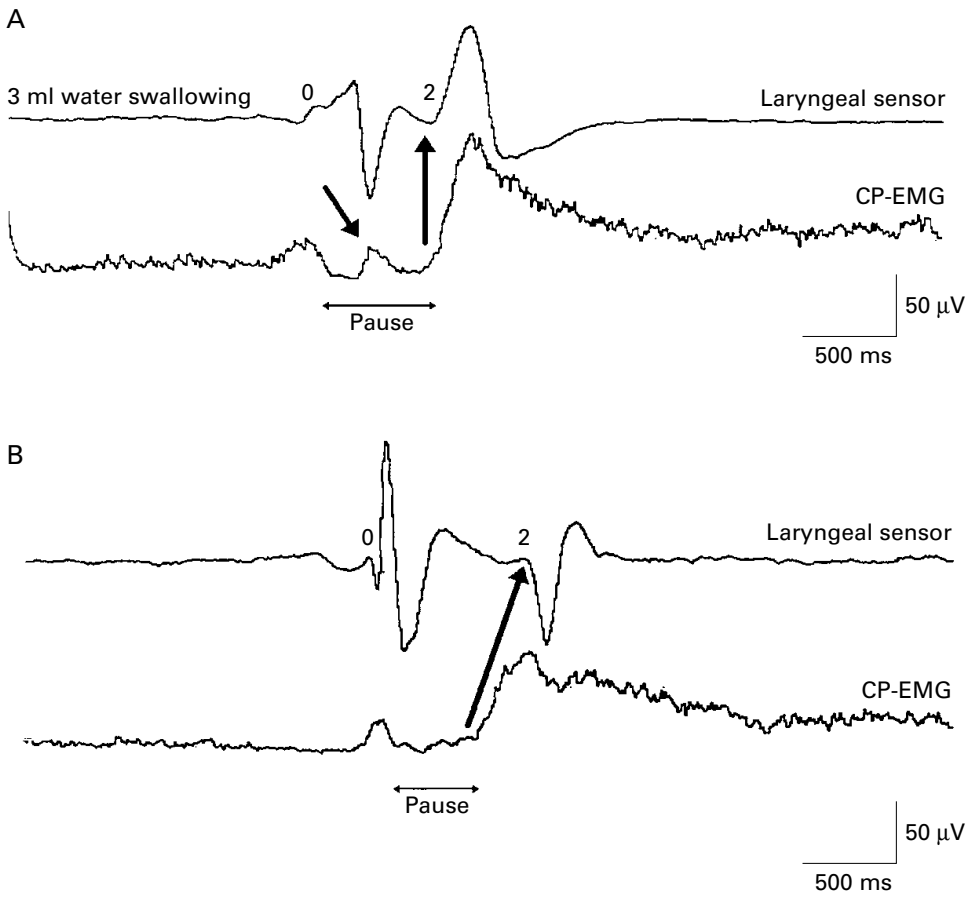

Figure 4 Laryngeal sensor signals (top traces in each pair) and CP-EMG activities (lower traces in each pair) recorded from two dysphagic patients with $M y D$ (in averaged recordings). In patient $A$, unexpected motor unit burst activity was seen within the $C P-E M G$ pause (oblique arrow) while swallowing $3 \mathrm{ml}$ water. The CP-EMG pause was shortened and the pause ended prematurely before the larynx had descended from its superior position (oblique arrow) in patient B. the laryngeal elevator muscles will have a reflex contraction and the laryngeal relocation time (0-2 time interval) will be normal. ${ }^{24}{ }^{36}$

It can be speculated that CNS involvement might be expected to trigger the cortical drive to be transmitted into the reflex swallow at an interneuron level of the bulbar swallowing centre. The significant prolongation of the A-0 interval found only in patients with MyD having CNS signs and symptoms might be supportive data for this speculation.

\section{(3) SLOWING IN PHARYNGEAL PHASE OF}

SWALLOWING

As a third swallowing abnormality, the duration of the swallowing reflex (0-2 time interval of the laryngeal relocation time) was significantly longer in MyD than in normal controls. The finding of prolongation of SM muscle excitation during swallowing (A-C interval) accompanying prolongation in the A-0 interval was the most significant finding. These two findings may indicate that the pharyngeal phase of swallowing is slow for transporting the bolus into the upper oesophageal sphincter. The prolongation in the duration of the swallowing reflex is similar to that found in myasthenia gravis $^{35}$ and in inflammatory myopathy ${ }^{23}$ but is somewhat contrary to that reported in amyotrophic lateral sclerosis with suprabulbar palsy, where the duration of the swallowing reflex is normally preserved. ${ }^{24} 37$ The prolongation activity of the weak laryngeal elevators in MyD to keep the larynx at an anterosuperior relocation position during swallowing must be the cause of the longer duration of A-C interval of SM-EMG and the 0-2 time interval of the laryngeal sensor movements in individual bases. The weakness of the pharyngeal muscles was demonstrated manometrically in $\mathrm{MyD}^{8-11}$ and it has been reported that the duration of the pharyngeal contraction is also longer than normal. ${ }^{68}$ Our findings are compatible with these results.

\section{(4) INCREASE OF THE SWALLOWING JITTER}

The fourth swallowing abnormality in $\mathrm{MyD}$ was the significant increase of swallowing jitter. The range of swallowing jitter would be expected to increase in acute problems of oropharyngeal swallowing and it increased markedly in cases of acute muscular disease such as myasthenia gravis ${ }^{23} 35$ and in acute strokes with dysphagia. ${ }^{23} \mathrm{As} \mathrm{MyD}$ is a chronic disease with a slowly progressive course, the increasing range of jitter was unexpected. It may result from weakness of the laryngeal elevators. The significant difference in jitter values between patients with $\mathrm{MyD}$ and those with myotonia congenita might be explained by the dystrophic changes in MyD. The significant correlation between the duration of the disease and the increase in jitter values may be related to the increase in severity of the laryngeal elevator muscle weakness due to the dystrophic pattern as the disease reaches an advanced stage. However, the myotonic contractions changing their condition from one swallow to 
Successive $3 \mathrm{ml}$ of water swallowing
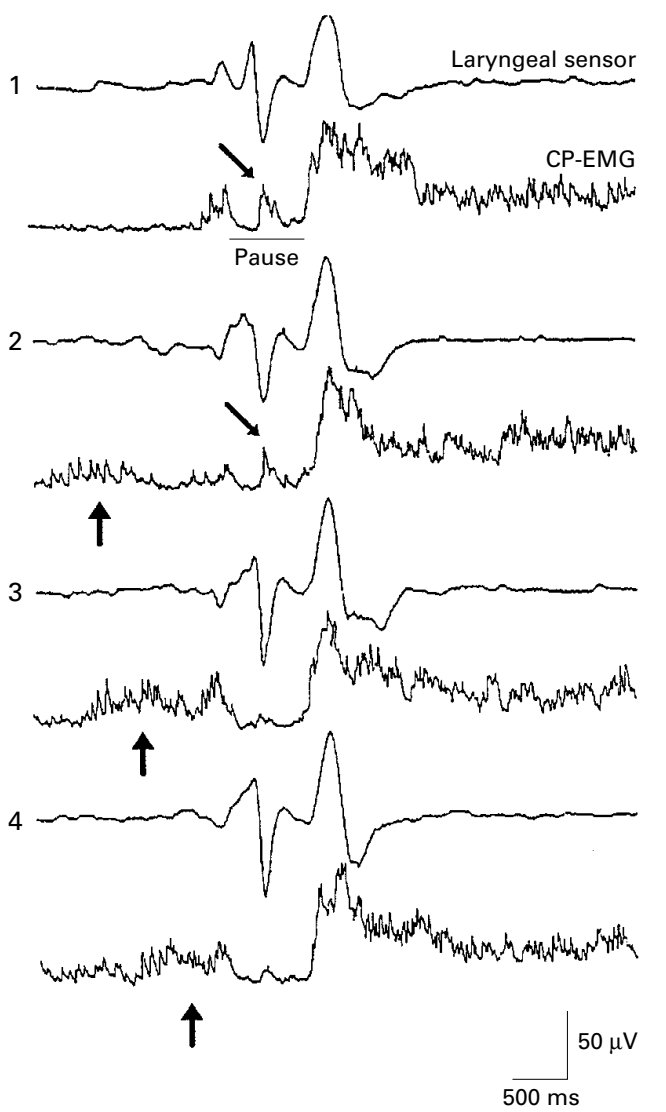

Figure 5 Four successive swallowing traces obtained from a dysphagic patient while swallowing $3 \mathrm{ml}$ water. Note the unexpected motor unit burst activity within CP-EMG pause (oblique arrow) and the variability of the tonic activity of CP-EMG during rest and foreburst just before the CP-EMG pause (vertical arrows).

another cannot be ignored in patients with MyD and could have a role in increasing jitter values.

(5) ABNORMALITIES IN THE CRICOPHARYNGEAL MUSCLE OF THE UPPER OESOPHAGEAL SPHINCTER In $60 \%$ of patients with $\mathrm{MyD}$, the $\mathrm{CP}$ muscle of the upper oesophageal sphincter was found to be normal electrophysiologically both in resting tonic activity and during swallowing. This is by contrast with the results of manometric studies, in which a marked reduction in resting tone of the upper oesophageal sphincter was found. . $^{81011}$ Evidence for neural dysfunction manifested by abnormalities in completeness and coordination of sphincter relaxation was not detected in patients with MyD. It was also reported that myotonia could not be seen around the upper oesophageal sphincter..$^{9-11} \mathrm{On}$ the other hand, Siegel et al found that the duration of relaxation of the upper oesophageal sphincter was prolonged. This controversy among different reports must be due to different technology and methodology. In the minority of patients (five) with MyD, who had also clinical dysphagia, there were some abnormalities akin to hyperreflexive sphincter usually encountered in patients with suprabulbar palsy, due to the involvement of pyramidalcorticobulbar motor fibres. ${ }^{2436}$ As the fifth electrophysiological abnormality of swallowing, this finding could not be explained either by the weakness or myotonia of the striated muscle of the CP sphincter. Alhough we have found some EMG changes that could be attributed to myotonia, they were not remarkable. Because all of them were in patients who showed signs and symptoms suggesting CNS involvement, they might be related to brain stem mechanisms.

WHAT ARE THE MECHANISMS OF DYSPHAGIA IN MYD?

Although five swallowing abnormalities were encountered in this study, we suggest that there are three different factors that may be involved in the problems of oropharyngeal swallowing in MyD.

(1) Myopathic weakness in jaw, buccal, tongue, submental and pharyngeal constrictor muscles may be responsible for the problems of bolus formation in the mouth (oral phase problem) and slow transit of the bolus along the pharynx (pharyngeal phase problem).This conclusion is supported by the frequent findings of piecemeal deglutition and abnormal dysphagia limits. The prolongation of the reflex swallowing, shown by 0-2 laryngeal sensor movements individually and long duration of SM-EMG, which was statistically and individually significant in patients with dysphagia, are the other supportive pieces of evidence.

(2) Myotonia encountered in oropharyngeal muscles in $\mathrm{MyD}$ is a probable contributing factor to the triggering of the swallowing reflex in some patients and in some swallows due to its variability and changeable nature in time. It may also contribute negatively to the safety of deglutition as it may interfere with the usual contractions of SM muscles during successive swallows. This idea is partly supported by the variability in SM muscles measured from the A-0 interval and from the increasing range of swallowing jitter.

(3) The third factor is speculative, but we provided some data that can only be explained by involving brain stem neural mechanisms. The interneurons in the reticular formation linked with the corticobulbar-pyramidal nerve fibres at the level of the medullary swallowing centre may be involved in MyD. The dysfunction of the interneurons related to deglutition is probably responsible for the triggering difficulties of voluntarily initiated swallows in some cases. Some inhibitory effects of the descending impulses may not be transmitted to the related motor neurons due to the lack of transmission in the interneurons situated in the reticular formation at the medullary level.

The organisation of deglutition at the medullary level is well known through experimental studies. ${ }^{20}{ }^{38-40}$ Such an approach can also explain the the premature closure and shortening of the CP-EMG pause encountered in some dysphagic patients in addition to a delay in triggering of the swallowing reflex. It has recently been shown that in addition to the characteristic muscular symptoms, patients with MyD often show CNS symptoms including apathy, hypersomnia and mild mental 
impairment ${ }^{13143041}$ and abnormal cranial MRI findings. ${ }^{42-44}$

In $\mathrm{MyD}$, neuronal loss has been described in the dorsal raphe nucleus, the superior central nucleus, and the medullary reticular forma$\operatorname{tion}^{45} 46$ in which the autonomic respiratory centre is thought to be located. The swallowing centre is also considered to be located at the same medullary region. ${ }^{20}{ }^{39}$ The nature of swallowing dysfunction often encountered in $\mathrm{MyD}$ awaits further studies especially into the role of brain stem mechanisms.

This study is supported by a grant from the Turkish Scientific and Technological Research Council (TUBITAK) (project SBAG-1739), We thank Assistant Professor Neșe Celebisoy for her invaluable help in preparing this manuscript.

1 de Die Smulders CE, Höweler CJ, Thijs C, et al. Age and causes of death in adult onset myotonic dystrophy. Brain 1998;121:1557-1563.

2 Garrett JM, DuBose Jr TD, Jackson JE, et al. Esophageal and pulmonary disturbance in myotonia dystrophica. Arch and pulmonary disturbance $1969 ; 123: 26-32$.

3 Hughes DTD, Swann JC, Gleason JA, et al. Abnormalities in swallowing associated with dystrophica myotonica. Brain 1965;88:1037-42.

4 Pruzanski W. Respiratory tract infection and silent aspiration in myotonic dystrophy. Dis Chest 1962;42:608-10.

5 Gillam PM S. Respiration in dystrophia myotonica. Thorax 1964;19:112-20

6 Harvey JC, Sherbourne DH, Siegel CI. Smooth muscle involvement in myotonic dystrophy. Am f Med 1965;39:8190.

7 Bungener C, Jouvent R, Delaporte C. Psychopathological and emotional deficits in myotonic dystrophy. $\mathcal{F}$ Neurol Neurosurg Psychiatry 1998;65:353-6.

8 Siegel CL, Hendrix TR, Harvey JC. The swallowing disorder in myotonia dystrophica. Gastroenterology 1966;50: 541-50.

9 Swick HM, Werlin SL, Dodds WJ, et al. Pharyngoesophageal motor function in patients with myotonic dystrophy. Ann Neurol 1981;10:454-7.

10 Eckardt VF, Nix W, Kraus W, et al. Esophageal motor function in patients with myotonic muscular dystrophy. Gastroenterology 1986;90:628-35.

11 Constantini M, Zaninotto G, Anselmino M, et al. Esophageal motor function in patients with myotonic dystrophy. Dig Dis Sci 1996;41:2032-8.

12 Mathieu J, De Braekeeler M, Prevast C, et al. Myotonic dystrophy: clinical assessment of muscular disability on an isolated population with presumed homogenous mutation. Neurology 1992;42:203-8.

13 Rubinsztein JS, Rubinsztein DC, Goodburn S, et al. Apathy and hypersomnia are common features of myotonic dystrophy. F Neurol Neurosurg Psychiatry 1998;64:510-15.

14 Van der Meche FGA, Bogaard JM, van der Sluys JCM, et al. Daytime sleep in myotonic dystrophy is not caused by sleep apnea. I Neurol Neurosurg 1994;57:626-8.

15 Ertekin C, Pehlivan M, Aydoğdu I, et al. An electrophysiological investigation of deglutition in man. Muscle ological investigation
Nerve 1995; 18:1176-86.

16 Ertekin C, Aydoğdu I, Yüceyar N, et al. Effects of bolus volumes on the oropharyngeal swallowing: an electrophysiological study in man. Am f Gastroenterol 1997:92:204953.

17 Donner MW, Bosma JF, Robertson DL. Anatomy and physiology of the pharynx. Gastrointest Radiol 1985;10:196212 .

18 Gay T, Rendell JK, Spiro J. Oral and laryngeal muscle coordination during swallowing. Laryngoscope 1994;104:341-9.

19 Perlman AL, Christenson J. Topography and functional anatomy of the swallowing structures. In:Perlman AL, Schulze Delrieu KS, eds. Deglutition and its disorders. San Diego, Singular Publication Group 1997:15-42.
20 Miller AJ. Deglutition [review]. Physiol Rev 1982;62:12984

21 Dodds WJ, Stewart ET, Logeman JA. Physiology and radiology of the normal oral and pharyngeal phase of swallowing. AfR Am f Roentgenol 1990;154:953-63.

22 Ertekin C. Clinical diagnosis and electrodiagnosis of swallowing disorder. In: Swenson MR, ed. Disorders of speech and swallowing. American Association of Electrodiagnostic Medicine. 19th Annual Continuing Education Course. Minnepolis, MN: Johnson Printing 1996:23-33.

23 Ertekin C, Aydoğdu I, Yüceyar N, et al. Electrodiagnostic methods for neurogenic dysphagia. Electroencephalogr Clin Neurophysiol 1998;109:331-40.

24 Ertekin C, Aydoğdu İ, Yüceyar N, et al. Pathophysiological mechanisms of oropharyngeal dysphagia in amyotrophic lateral sclerosis. Brain 2000;123:124-40.

25 Ertekin C, Aydoğdu I, Yüceyar N. Piecemeal deglutition and dysphagia limit in normal subjects and in patients with swallowing disorders. I Neurol Neurosurg Psychiatry 1996; 61:491-6.

26 Rasley A, Logeman JA, Kahrilas PJ, et al. Prevention of barium aspiration during videofluoroscopic swallowing studies: value of change in posture. AfR Am f Roentgenol 1993;160:1005-9.

27 Logeman JA, Radermaker AW, Powloski BR, et al. Effects of postural change on aspiration in head and neck surgical patients. Otolaryngol Head Neck Surg 1994;110:222-7.

28 Shanahan T, Logeman JA, Rodermaker B, et al. Chin-down posture effects on aspiration in dysphagic patients. Arch Physiol Med Rehabil 1993;74:736-9.

29 Ertekin C, Kıylıoğlu N, Tarlacı S, et al. Electrophysiological identification of voluntary and reflex swallows. Electroencephal Clin Neurophysiol 1998;60(supp):106.

30 Harper PS. Myotonic dystrophy, 2nd ed. London, UK: WB Saunders, 1989.

31 Schuman BM, Rinaldo JA, Darnley JD. Viseral changes in myotonic dystrophy. Ann Intern Med 1965;63:793-9.

32 Pruzanski W, Profis A. Dysfunction of alimentary tract in myotonic dystrophy. $\mathcal{F}$ Med Sci 1966;2:59-64.

33 Rönnblom A, Forsberg H, Danielsson A. Gastrointestinal symptoms in myotonic muscular dystrophy. Scand $\mathcal{f}$ Gastroenterol 1996;31:654-7.

34 Willig TN, Paulus J, Lacau Saint Guily J, et al. Swallowing problems in neuromuscular disorders. Arch Physiol Med Rehabil 1994;75:1175-81.

35 Ertekin C, Yüceyar N, Aydoğdu I. Clinical and electrophysiological evaluation of dysphagia in myastenia gravis. $\mathcal{F} \mathrm{Neu}$ rol Neurosurg Psychiatry 1998;65:848-56.

36 Ertekin C, Aydoğdu İ, Tarlacı S, et al. Mechanisms of dysphagia in suprabulber palsy with lacunar infarct. Stroke 2000;31:1370-6.

37 Hughes TA, Wiles CM. Palatal and pharyngeal reflexes in health and motor neuron disease. 7 Neurol Neurosurg Psychiatry 1996;61:96-8.

38 Jean A, Car A. Inputs to swallowing medullary neurons from the peripheral afferent fibers and the swallowing cortical area. Brain Res 1979;178:567-72.

39 Miller AJ.The search for the central swallowing pathway. The quest for clarity [review]. Dysphagia 1993;8:189-94.

40 Zoungrana OR, Amri M, Car A, et al. Intracellular activity of motor neurons of the rostral nucleus ambigius during swallowing in sheep. F Neurophysiol 1997;77:909-22.

41 Ashizawa T. Myotonic dystrophy as a brain disorder [editorial]. Arch Neurol 1998;55:291-2.

42 Bachmann G, Damian MS, Koch M, et al. The clinical and genetic correlates of MRI findings in myotonic dystrophy. Neuroradiology 1996;38:629-35.

43 Miaux Y, Chiras J, Eymard B, et al. Cranial MRI findings in myotonic dystrophy. Neuroradiology 1997;39:166-70.

44 Huber SJ, Kissel JT, Shuttleworth EC, et al.Magnetic resonance imaging and clinical correlates of intellectual impairment in myotonic dystrophy. Arch Neurol 1989;46:536-40.

45 Ono S, Konda F, Takahashi, et al. Neuronal loss in the medullary reticular formation in myotonic dystrophy: a clinicopathological study. Neurology 1996;46:228-31.

46 Ono S, Takahashi K, Jinna K, et al. Loss of catecolaminergic neurons in the medullary reticular formation in myotonic muscular dystrophy. Neurology 1998;51:1121-4. 